\title{
Hydrocarbon Spill Management Through Leak Localization in Natural Gas Pipeline
}

\author{
Anthony Chemazu Igbojionu, Ubanozie Julian Obibuike, Mathew Udechukwu, \\ Chioma Deborah Mbakaogu, Stanley Toochukwu Ekwueme
}

Department of Petroleum Engineering, Federal University of Technology, Owerri, Nigeria

\section{Email address:}

stanleyekwueme@yahoo.com (S. T. Ekwueme)

\section{To cite this article:}

Anthony Chemazu Igbojionu, Ubanozie Julian Obibuike, Mathew Udechukwu, Chioma Deborah Mbakaogu, Stanley Toochukwu Ekwueme. Hydrocarbon Spill Management Through Leak Localization in Natural Gas Pipeline. International Journal of Oil, Gas and Coal Engineering. Vol. 8, No. 6, 2020, pp. 137-142. doi: 10.11648/j.ogce.20200806.13

Received: September 21, 2020; Accepted: October 6, 2020; Published: November 16, 2020

\begin{abstract}
It is important that leaks are detected early in pipelines. The need for prompt and accurate leak detection becomes more crucial when the pipeline content is gaseous. Remedial actions require that the leak location be determined in any leak incidence. Accurate leak localization will not only save cost but will enhance remedial actions such as replacement and repairs of damaged pipeline sections, clean-up of affected ecological systems and direct inspection of degree of damage. This information will aid in understanding the causes and effects of the leak. This paper presents a mathematical model for determination of the location of leak in a natural gas pipeline. The mathematical approach employed a mass balance approach to the modification of the Weymouth's gas transportation equation in a horizontal natural gas pipeline. The pipeline under consideration was divided into two sections at the advent of leak. Before the leak point the pipeline cross section is represented as the upstream section while the downstream represents the section ahead of the leak point. The mathematical model herein was developed with reference to the downstream section of the pipeline. The results showed good accuracy with other leak location models available in literature and was also verified to be correct and within acceptable error limits when compared with actual field data.
\end{abstract}

Keywords: Downstream Section, Weymouth, Mathematical Model, Natural Gas

\section{Introduction}

Hydrocarbon spills occur frequently in pipeline systems. In most cases, spills of pipeline content are as a result of pipeline leaks. Pipeline leak can be defined as the loss of material mass from a pipeline. The leak could occur as small opening, or rupture in a pipeline leading to the escape of fluid. Surveying leak is done as a systematic inspection with the aim of finding leaks in pipelines.

Leaks in pipeline represent an important problem in pipeline operation. The problem of pipeline leakage poses great environmental and financial challenges [1]. The situation becomes more profound when the leak occurs close to residential areas and much more disastrous when the fluid is gas. Therefore, it is desirable that the appearance of a leak in a pipe be identified and located as soon as possible. Thus, detection and location of leaks become the most important components of the supervision system and control of pipelines. Early detection and management of leak is only achieved by use of competitive and efficient leak detection methods [2, 3].

Costs of pipeline leaks can be grouped into four main groups [4, 5]: Life and property Loss, Direct cost of lost product and line downtime, Cost of Environmental cleanup, Fines and law suits. Quick and reliable leak detection systems require real-time leak detection system. Most pipeline operators recognize this and install real-time systems capable of detecting leak as soon as possible with minimal product loss and potential hazard to the public.

The methods for leak detection fall into two broad categories; these are externally (released fluid detection) and internally (observing hydraulic behavior) based methods. The externally based methods are also referred to as physical inspection methods and is done to identify the location and size of leaks. Physical inspection consists of gas sampling; soil monitoring; flow-rate monitoring; and acoustic-, optical-, and satellite-based hyperspectral imaging. Usually, the physical inspection can result in an accurate detection of the location and size of a leak, but this comes with the expense of production shutdown and the 
high cost/long time to run the physical detection, which is very crucial in a long-distance gas pipeline [6]. The internal methods employ mathematical modelling of pipeline hydraulic parametres such as pressure, temperature, volume, flowrate etc. $[7,8]$. The Mathematical-modeling approach detects a gas leak by solving the governing mass-conservation, momentumconservation, and energy- balance equations, thus leading to a quick evaluation at much lower cost. It also has the advantages of monitoring the system continuously and noninterference with pipeline operations. One of the limitations of the modeling method is that it requires flow parameters, which are not always available. Leak detection from mathematical modeling also has a higher uncertainty than that from physical inspection.

Many researchers have conducted investigations on gas transient flow in pipelines to detect leaks $[9,10]$.

Obibuike et al [11] developed an analytical model for determination of leak location in natural gas pipeline. Their method uses the upstream section of the pipeline.

Jin [12] worked on determination of leak location in pipelines. His method uses the concept of negative pressure wave detected by pressure transducers placed strategically along the pipeline. Although his method yields accuracy with an average error of only about $0.28 \mathrm{~km}$, it is capital intensive and restrictive in application. Its accuracy is highly dependent on the accuracy of the external pipeline instrumentation which is subject to theft or sabotage.

Mashford [13] worked on negative pressure wave and introduced a wavelet algorithm to detect and locate leak in pipeline. His method allowed small leaks to be detected by noise recognition. The wavelet transform is a signal processing method that have been widely used.

Ferrante et al [14] developed a method of leak detection that is transient-based. His procedure relies on the extracted pressure signals that emanate from faults in pipes. When these signals are processed by using wavelet transform modulus.
Wang and Carroll [15] analyzed the real-time data with a transient model to detect gas- and liquid-pipeline leakage. Stochastic processing and noise filtering of the meter reading were used to reduce the impact of noise. The correlations for diagnosing the leak location and amount are derived on the basis of the online real-time observation and the readings of pressure, temperature, and flow rate at both ends of the pipeline.

Reddy et al. [16] built a dynamic simulation model by use of a transfer-function model for online state estimation and leak detection in a gas pipeline. The model reduced the computational time, while obtaining accurate state estimation from noisy measurements. The computation required all available measurements of pressure and flow rate.

Da silver [17] used pressure transient analysis model to estimate leakages in pipes. His method was based on the analysis of continuous measurement of pressure at segments of the pipeline. This method revealed signs of efficient and real-time location of leaks. It is efficient both for single leaks and for multiple leaks.

The objective of this paper is to develop analytical mathematical model to locate leak in natural gas pipeline. The model is determined from the downstream section of the pipeline at the advent of leak. The result from the modelled data is to be compared with experimental data from actual field operations.

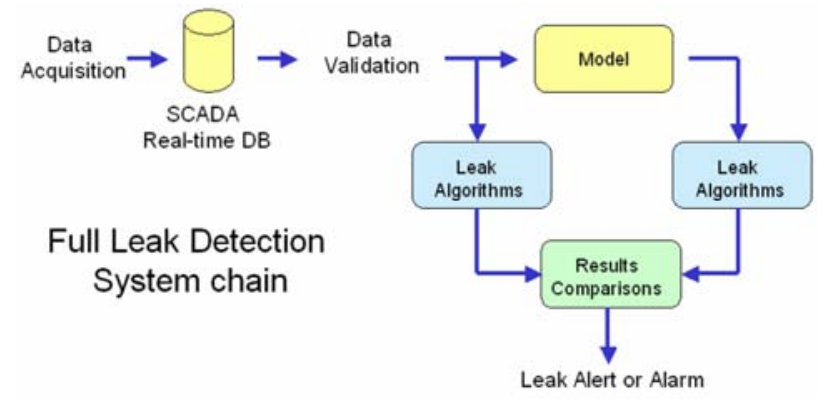

Figure 1. Leak detection system Cycle [18, 19].

Table 1. Classification of Leak Detection systems [18, 19].

\begin{tabular}{lll}
\hline Non-continuous Systems & Continuous Systems & Internal \\
\hline Inspection by helicopter & External & Mass/Volume Balance \\
\hline Smart pigging & Acoustic Emission Method & Negative Pressure Wave \\
Use of Trained dogs & Fibre optic Method & Real Time Transient Method \\
& Vapour Sampling & Pressure Point Analysis \\
& Vapour Sensing Cable & Digital Signal Processing \\
& Soil Monitoring & Statistical Method \\
& & \\
\hline
\end{tabular}

\section{Methods}

The methodology deals with the development of model to account for leak location in pipeline. The model was developed by considering the downstream section of the leaking pipeline.

If we consider figure 2 and figure 3 below

Let $Q_{1}$ be the inlet gas flowrate of the no leak case in $\mathrm{cuft} / \mathrm{hr}$

$\mathrm{Q}_{2}=$ the output gas flowrate of the no leak case in cuft/hr

$Q_{\text {down }}=$ the flowrate at the output section of the pipeline in

$$
\begin{aligned}
& \mathrm{cuft} / \mathrm{hr} \\
& \quad P_{\text {down }}=\text { the output pressure in psi }
\end{aligned}
$$

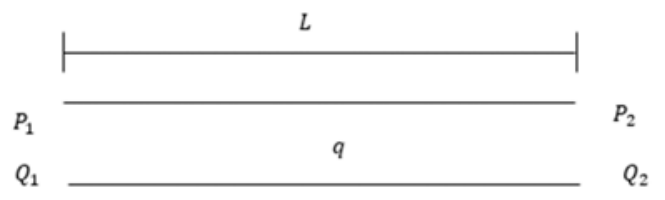

Figure 2. Pipeline Condition for no Leak.

From figure 2, it is seen that the flowrate is same throughout the whole section of the pipeline since flow is in 
steady state.

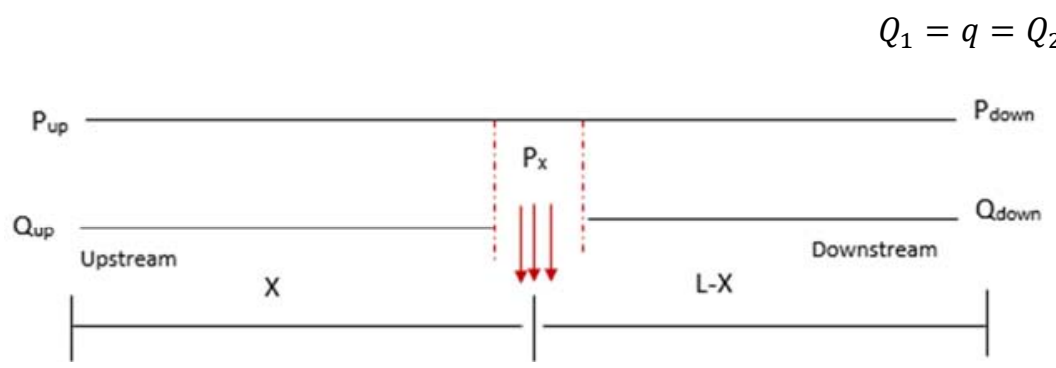

Figure 3. Pipeline Condition for the case of Leak.

Natural gas flow in horizontal pipeline is modelled by the Weymouth's equation as given below.

$$
q=3.23 \frac{T_{b}}{P_{b}} \sqrt{\frac{1}{f}} \sqrt{\frac{\left(P_{1}^{2}-P_{2}^{2}\right) D^{5}}{\gamma \bar{T} \bar{z} L}}
$$

Where

$\mathrm{q}=$ gas flowrate in cuft $/ \mathrm{hr}$

$\mathrm{T}_{\mathrm{b}}=$ base temperature $\left(60^{\circ} \mathrm{F}\right.$ or $\left.520^{\circ} \mathrm{R}\right)$

$\mathrm{P}_{\mathrm{b}}=$ base pressure $(14.73 \mathrm{psia})$

$\mathrm{f}=$ friction factor

$\mathrm{P}_{1}=$ inlet pressure, $\mathrm{psia}$

$\mathrm{P}_{2}=$ outlet pressure, $\mathrm{psia}$

$\gamma=$ gas gravity

$\bar{T}=$ average gas temperature, ${ }^{\circ} \mathrm{R}$

$\bar{Z}=$ gas compressibility factor

$L=$ Length of the pipeline, miles

The Weymouth equation given above in equ (2) can be adjusted to give

$$
q=3.23 \frac{T_{b}}{P_{b}} \sqrt{\frac{1}{f}}\left(\frac{D^{5}}{\gamma \bar{z} \bar{T} L}\right)^{0.5}\left[\left(P_{1}^{2}-P_{2}^{2}\right)^{0.5}\right]
$$

\subsection{Developing Leak Equation for Natural Gas Pipeline}

The general equation for natural gas flow in pipeline when there is no leak is given in compact form as

$$
q=k\left(P_{1}^{2}-P_{2}^{2}\right)^{0.5}
$$

This is similar to the Weymouth's equation given above where $\mathrm{k}$ being the constant of proportionality represents the non-pressure terms in the RHS of the Weymouth's equation. Thus $\mathrm{k}$ is given as follows

$$
k=3.23 \frac{T_{b}}{P_{b}} \sqrt{\frac{1}{f}}\left(\frac{D^{5}}{\gamma \bar{Z} \bar{T} L}\right)^{0.5}
$$

Leak occurrence divides the pipeline section into two: The upstream and the downstream sections respectively

Considering the downstream section of the pipe. The assumption is that flowrate in upstream section of the pipe is uniform while the flowrate in downstream section is also uniform and equal to the output flowrate during leak, $Q_{\text {down }}$. Thus in each section, flowrate remains uniform but changes as another section is approached.

In the downstream section of the pipeline,

$$
Q_{\text {down }}=k_{\text {down }}\left(P_{x}^{2}-P_{\text {down }}^{2}\right)^{0.5}
$$

Where

$Q_{\text {down }}=$ the output flowrate during leak at the output section of the pipeline in cuft $/ \mathrm{hr}$

$P_{\text {down }}=$ the output pressure during leak in psi

$k_{\text {down }}=$ Constant which comprise all the other terms in the Weymouth's equation.

$$
k_{\text {down }}=3.23 \frac{T_{b}}{P_{b}} \sqrt{\frac{1}{f}}\left(\frac{D^{5}}{\gamma \bar{z} \bar{T}(L-X)}\right)^{0.5}
$$

Comparing equation 7 with equation 6 we have that

$$
\frac{Q_{\text {down }}}{q}=\frac{k_{\text {down }}\left(P_{x}^{2}-P_{\text {down }}{ }^{2}\right)}{k\left(\Delta P^{2}\right)^{0.5}}
$$

Putting in the values of $k_{\text {down }}$ and $k$ the equation becomes

$$
\frac{Q_{\text {down }}}{q}=\frac{3.23 \frac{T_{b}}{P_{b}} \sqrt{\frac{1}{f}}\left(\frac{D^{5}}{\gamma \overline{\bar{z}} \bar{T}(L-X)}\right)^{0.5}\left(P_{x}{ }^{2}-P_{\text {down }}{ }^{2}\right)^{0.5}}{3.23 \frac{T_{b}}{P_{b}} \sqrt{\frac{1}{f}}\left(\frac{D^{5}}{\gamma \overline{\bar{Z}} \bar{T} L}\right)^{0.5}\left(P_{1}{ }^{2}-P_{2}{ }^{2}\right)^{0.5}}
$$

Solving the equation above gives

$$
\frac{Q_{\text {down }}}{q}=\frac{L^{0.5}\left(P_{x}{ }^{2}-P_{\text {down }}\right)^{0.5}}{(L-X)^{0.5}\left(P_{1}{ }^{2}-P_{2}{ }^{2}\right)^{0.5}}=\left[\frac{L\left(P_{x}{ }^{2}-P_{\text {down }}{ }^{2}\right)}{(L-X)\left(P_{1}{ }^{2}-P_{2}{ }^{2}\right)}\right]^{0.5}
$$

Squaring both sides of the equation above gives

$$
\left(\frac{Q_{\text {down }}}{q}\right)^{2}=\frac{L\left(P_{x}^{2}-P_{\text {down }}{ }^{2}\right)}{(L-X)\left(P_{1}^{2}-P_{2}^{2}\right)}
$$

Thus

$$
(L-X)=\left(\frac{q}{Q_{\text {down }}}\right)^{2} \frac{L\left(P_{x}^{2}-P_{\text {down }}{ }^{2}\right)}{\left(P_{1}{ }^{2}-P_{2}^{2}\right)}
$$

Making X the subject of formula gives

$$
\begin{aligned}
& X=L-\left[\left(\frac{q}{Q_{\text {down }}}\right)^{2} \frac{L\left(P_{x}^{2}-P_{\text {down }}{ }^{2}\right)}{\left(P_{1}^{2}-P_{2}^{2}\right)}\right] \\
& X=L\left\{1-\left[\left(\frac{q}{Q_{R}}\right)^{2} \frac{\left(P_{x}^{2}-P_{\text {down }}{ }^{2}\right)}{\left(P_{1}{ }^{2}-P_{2}{ }^{2}\right)}\right]\right\}
\end{aligned}
$$

The above equation is used to determine the leak distance by considering flow from the downstream end of the pipeline.

\subsection{Simulation of the Model}

The sequence below describes the testing and use of the model to solve the problem of leak location in natural gas pipeline. The Data for this work was gotten from XYZ Gas Company that operates in the Niger Delta region. 


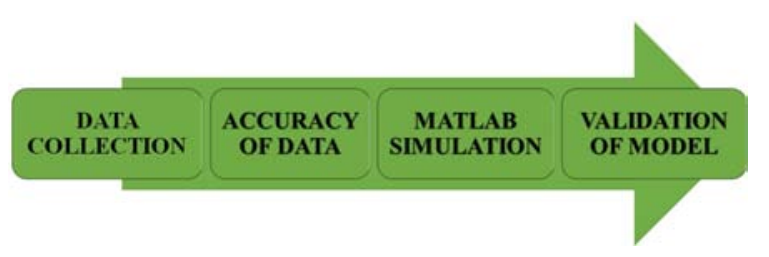

Figure 4. Simulation Flow Scheme.

Matlab software was used to run the simulation to determine the leak location

The input data for the pipeline operation is given below. The data correspond to leak data gotten from company's pipeline operation. The model developed shall be used to estimate the leak location and volume of leak for each case.

Table 2. Pipeline Input data.

\begin{tabular}{llll}
\hline \multirow{2}{*}{ Parameters } & Values & & \\
\cline { 2 - 4 } & Case 1 & Case 2 & Case 3 \\
\hline Pipeline length (miles) & 160 & 120 & 150 \\
Pipeline diameter (in.) & 15.5 & 12.09 & 14 \\
Inlet pressure (psia) & 1250 & 1000 & 1080 \\
Outlet pressure (psia) & 800 & 720 & 680 \\
Flowing fluid temp. $\left({ }^{\circ} \mathrm{F}\right)$ & 80 & 80 & 100 \\
Base temperature. $\left({ }^{\circ} \mathrm{F}\right)$ & 60 & 60 & 60 \\
Gas deviation factor & 0.85 & 0.88 & 0.95 \\
Gas specific gravity & 0.6 & 0.67 & 0.65 \\
Gas flowrate at inlet (MMscf/hr) & 4.365 & 1.746 & 2.679 \\
Output flowrate during leak (MMscf/hr) & 3.88 & 1.4 & 2 \\
Atmospheric pressure (psia) & 14.7 & 14.7 & 14.7 \\
Temperature at standard conditions $\left({ }^{\circ} \mathrm{R}\right)$ & 520 & 520 & 520 \\
Output pressure during leak (psia) & 671.73 & 678.33 & 755.78 \\
\hline
\end{tabular}

\section{Result and Discussions}

Results and discussions are given for the leak location. The result is validated and sensitivity analyses are performed on the three cases considered.

\subsection{Leak Location Results}

The results given below show the leak locations and the pressure in the pipeline at the point of leak, calculated from the various input variables from each case give in table 1 above.

Table 3. Leak location results for the cases considered.

\begin{tabular}{lll}
\hline Case & Leak Location (Miles) & Leak Location $(\mathbf{K m})$ \\
\hline case 1 & 139.5 & 224.4555 \\
case 2 & 86.48 & 139.1463 \\
case 3 & 34.94 & 56.21846 \\
\hline
\end{tabular}

From table 3, the leak location for case 1, case 2 and case 3 are 139.5 miles $(2224.5 \mathrm{~km}), 86.48$ miles $(139.1 \mathrm{~km})$ and 34.94 miles $(933.89 \mathrm{~km})$ respectively.

\subsection{Model Validation}

The table given blow shows the result calculated from the model and the one from the actual field

Table 4. Table for Validation of model.

\begin{tabular}{llll}
\hline Case & $\begin{array}{l}\text { Leak Distance } \\
\text { From Model }(\mathbf{k m})\end{array}$ & $\begin{array}{l}\text { Actual Field } \\
\text { Results }\end{array}$ & Absolute Error \\
\hline case 1 & 224.4555 & 224.2 & 0.2555 \\
case 2 & 139.1463 & 138.85 & 0.2963 \\
case 3 & 56.21846 & 56.45 & 0.23154 \\
case 4 & 224.4555 & 224.2 & 0.2555 \\
Average error & & & 0.25971 \\
\hline
\end{tabular}

The model is validated by comparison with the work of Jin [12] who worked on leak localization in natural gas pipeline using negative pressure wave. The average error of $0.28 \mathrm{~km}$. The Average error from the model is $0.26 \mathrm{~km}$. Thus the model gives result of higher accuracy than that proposed by Jin [12].

\subsection{Sensitivity Analyses}

For each of the following cases, the pressure profile for the leak and no leak case is given in graphical form.

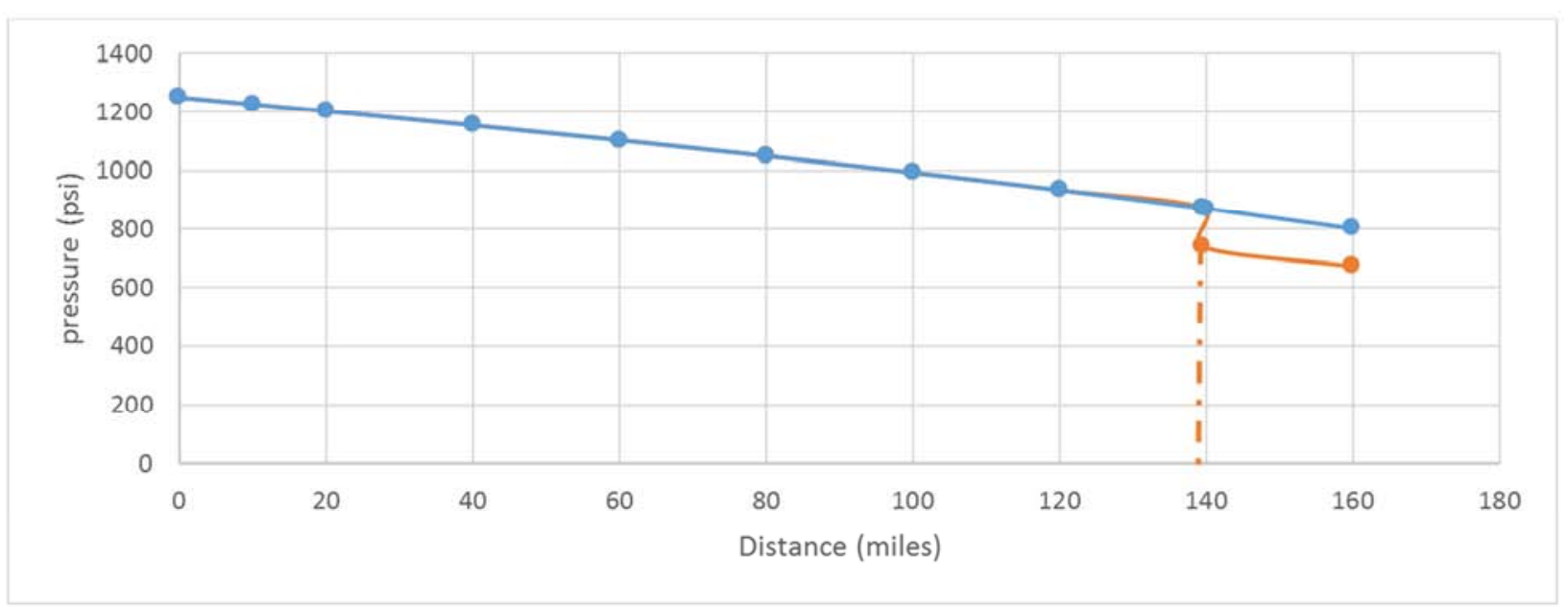

Figure 5. Pressure profile chart showing leak and no leak situations for case 1.

For case 1, the leak occurred at 139.5 miles from the inlet point. The pressure profile for the leak case never stabilized with the pressure profile for the no leak case. I.e. both pressures were never equal at a given location for the 
pipeline length and input parametres considered. This is because the leak occurred very close to the output end of the pipeline ant the remaining length available for the reduced pressure did not have enough distance and time to stabilize.

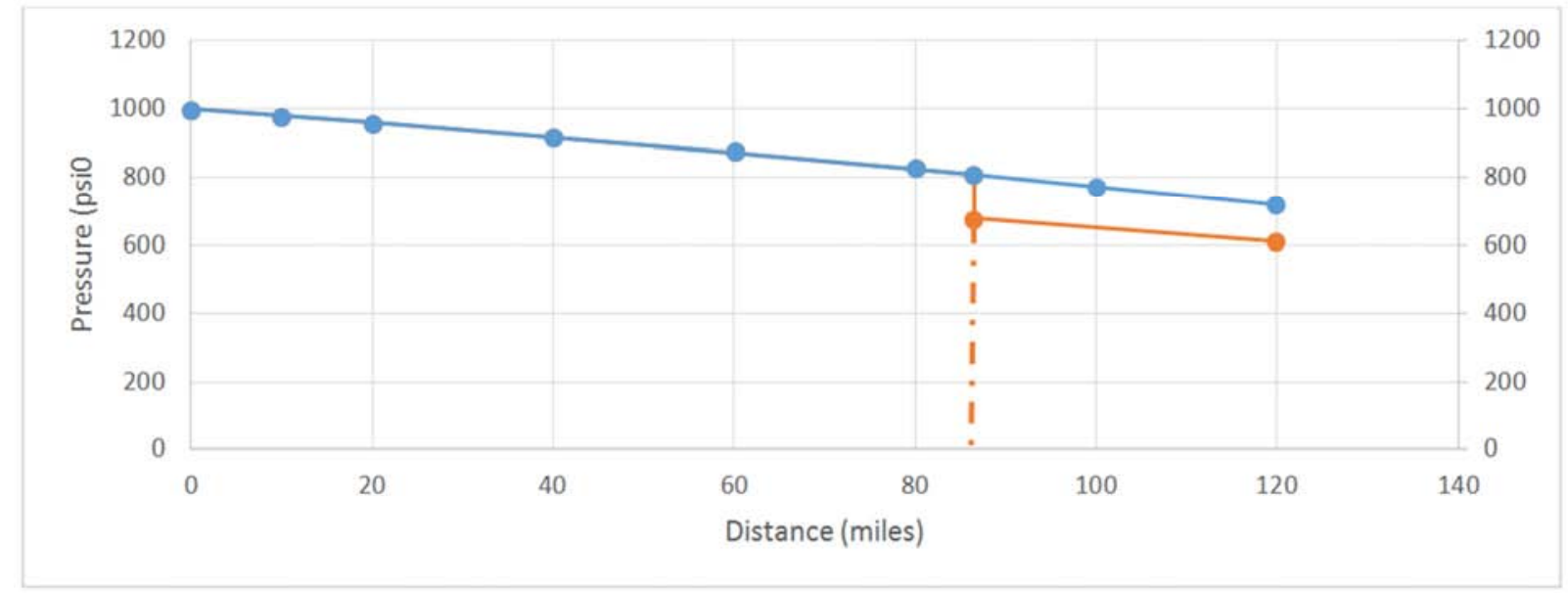

Figure 6. Pressure profile chart showing leak and no leak situations for case 2.

For case 6 , the leak occurred at 86.48 miles from the inlet point. The pipeline profile shows that the affected pressure profile due to leak never stabilized with the no leak pressure profile.

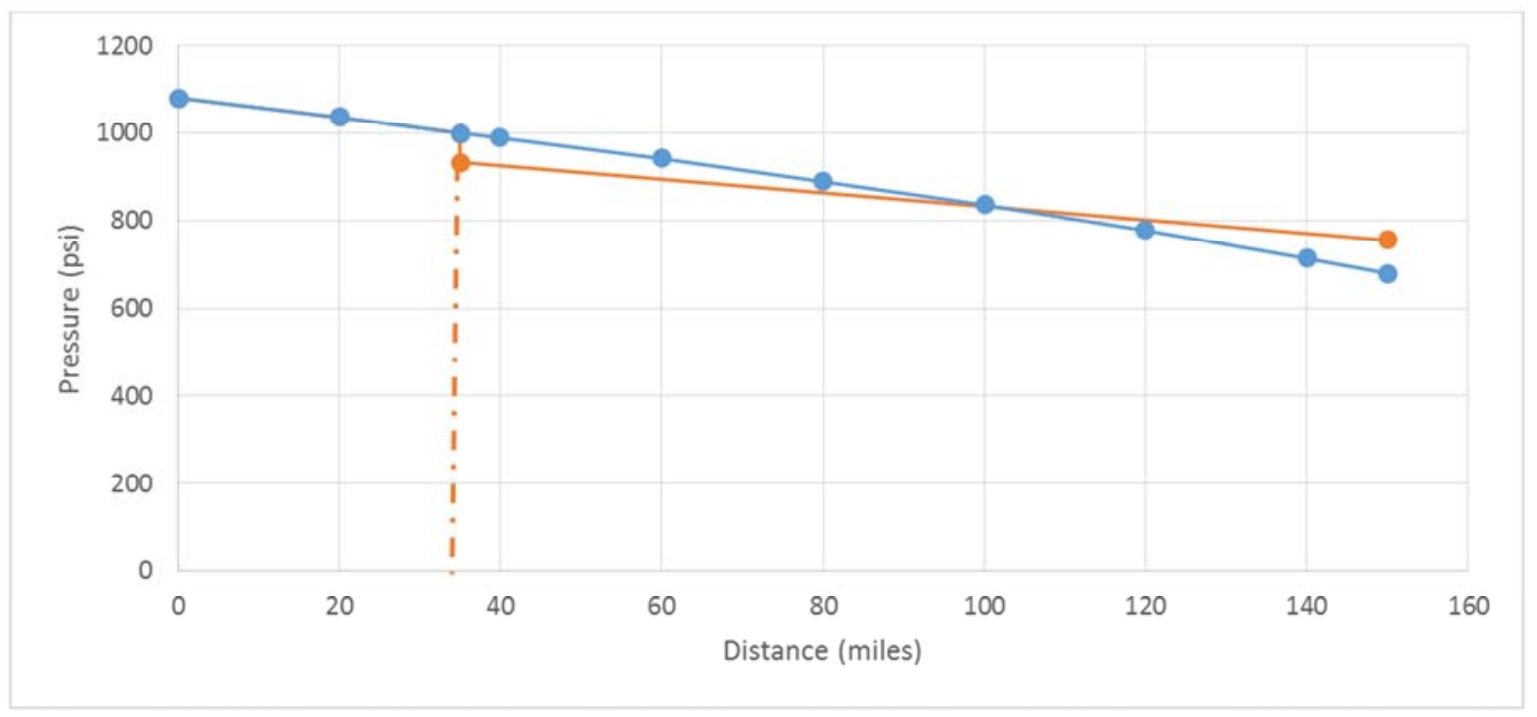

Figure 7. Pressure profile chart showing leak and no leak situations for case 3.

\section{Conclusion}

A leak location model has been developed for leak location in natural gas pipeline. The model has correctly estimated leak location for 3 cases. For all the cases the model proves good accuracy. The results were verified with actual data from leak occurrence. The developed estimated the leak location with an average error or only $0.26 \mathrm{~km}$ which is lower than the $0.28 \mathrm{~km}$ average error gotten by Jin (2019) in his work on leak location in natural gas pipeline using pressure wave techniques. The model for the location developed will help in management of natural gas spills.

The model is highly recommended to be used in pipeline monitoring and supervision to ensure safer pipeline operations. It is also recommended that the model be incorporated to the supervisory control and data acquisition unit (SCADA) where there is availability of pipeline monitoring devices like flowmetres and pressure gauges for effective and efficient functionality of the model.

\section{References}

[1] Ekwueme, S. T (2014). Model for pipeline leak detection in natural gas pipeline. Paper presented at the annual STCE paper presentation. Warri, Delta state.

[2] Balda Rivas, K. V. and Civan, F. (2013): Application of Mass Balance and Transient Flow Modeling for Leak Detection in Liquid Pipelines. Presented at the SPE Production and Operations Symposium, Oklahoma City, Oklahoma, USA, 23-26 March. SPE-164520-MS. 
[3] Ghazali, M. F. (2012). Leak detection using instantaneous frequency analysis ( $\mathrm{PhD}$ thesis), University of Sheffield, United Kingdom.

[4] Luopa, J. A. (2010) Leak Detection on Petroleum Pipelines. Worley Parsons Resources \& Energy. Colt Technologies, Edmonton, Alberta, Canada.

[5] Lowry, W., Dunn, S. Walsh, R., Merewether, D. and Rao, D. (2000). Method and system to locate leaks in subsurface containment structures using tracer gases. US Patent 6035701.

[6] Gajbhiye, R. N. and Kam, S. I. (2008). Leak Detection in Subsea Pipeline: A Mechanistic Modeling Approach with Fixed Pressure Boundaries. Presented at the Offshore Technology Conference, Houston, 5-8 May. OTC-19347-MS.

[7] Kegang Ling, Guoqing Han, X. N, Chunming Xu, Jun He, Peng Pei, and Jun Ge. (2015): A New Method for Leak Detection in Gas Pipelines, Paper (SPE 1891568) accepted for presentation at the SPE/AAPG/SEG Unconventional Resources Technology Conference, Denver.

[8] Elliott, J., Fletcher, R., and Wrigglesworth, M. (2008): Seeking the Hidden Threat: Applications of a New Approach in Pipeline Leak Detection. Presented at the Abu Dhabi International Petroleum Exhibition and Conference, Abu Dhabi, 3-6 November. SPE-118070-MS.

[9] Hauge, E., Aamo, O. M., and Godhavn, J.-M. (2009): ModelBased Monitoring and Leak Detection in Oil and Gas Pipelines. SPE Proj Fac \& Const 4 (3): 53-60. SPE-114218PA.

[10] Boaz, L., Kaijage, S. and Sinde, R. (2014). An overview of pipeline leak detection and location systems. Pan African International Conference on Information Science, Computing and Telecommunications, (pp. 133-136).

[11] Obibuike U. J., Ekwueme S. T., Ohia, N. P., Igwilo, K. C., Onyejekwe, I. M., Igbojionu, A. C. (2019). Analytical Model for the Estimation of Leak Location in Natural Gas Pipeline.
International Journal of Oil, Gas and Coal Engineering. Vol. 7, No. 4, 2019, pp. 95-102.

[12] Jin Mingang (2019). Investigation on Parameters Affecting the Performance of Negative Pressure Wave Leak Detection Systems. Paper prepared for presentation at the PSIG Annual Meeting held in London, England.

[13] Mashford, J. (2009). An approach to leak detection in pipe networks using analysis of monitored pressure values by support vector machine. 3rd International Conference on Network and System Security, (pp. 534-539, 581).

[14] Ferrante, M., Brunone, B. and Meniconi, S. (2007). Wavelets for the analysis of transient pressure signals for leak detection. ASCE 133 (11), (pp. 1274-1282).

[15] Wang, S. and Carroll, J. J. 2007. Leak Detection for Gas and Liquid Pipelines by Online Modeling. SPE Proj Fac \& Const 2 (2): 1-9. SPE- 104133-PA.

[16] Reddy, H. P., Narasimhan, S., and Bhallamudi, S. M. (2006): Simulation and State Estimation of Transient Flow in Gas Pipeline Networks Using Transfer Function Model. Ind. Eng. Chem. Res. 45 (11): 3853-3863.

[17] Da Silva, V. H., Morooka, K., Guilherme, R., Da Fonseca, C. (2005) Leak detection in petroleum pipelines using a fuzzy system. Journal of Petroleum and Science and Engineering, Vol. 49, (pp. 223-228).

[18] Ekwueme, S. T (2014). A new mathematical model for pipeline leak detection in natural gas pipeline. Project submitted to Petroleum engineering Dept. FUTO.

[19] Obibuike, U. J. (2019). Real Time Estimation of Leak Location in a Natural Gas Pipeline - A Fluid Flow Modeling Approach. Ph. D Thesis submitted to Postgraduate school, FUTO, Owerri, Nigeria. 